Artigo

\title{
Problematizando as relações entre Matemática e Música na Educação Matemática
}

\author{
Problematizing the relations between Mathematics and Music in Mathematics Education \\ Problematizando las relaciones entre las matemáticas y la música en la Educación \\ Matemática
}

\author{
Alice Stephanie Tapia Sartori ${ }^{1}$ \\ [0000-0002-0442-6645] \\ Juliano Espezim Soares Faria ${ }^{2}$ \\ [0000-0002-3083-7851]
}

\begin{abstract}
Resumo
Neste artigo analisamos um conjunto de textos inseridos no campo de pesquisa da Educação Matemática que estabelecem relações entre matemática e música, publicados nas quatro últimas edições do Encontro Nacional de Educação Matemática (ENEM). Recorrendo à análise do discurso foucaultiana como metodologia, damos visibilidade às enunciações categorizadas a partir desses artigos, organizando-as a partir de 3 problematizações. Na primeira, fazemos considerações sobre a apropriação da música para o ensino de frações, levando em conta o contexto histórico da matemática grega e sobre o uso dos símbolos das notas musicais de acordo com seus tempos. Na segunda, analisamos enunciações que remetem a aspectos metodológicos naturalizados no ensino de matemática, a saber a ludicidade e o estímulo do interesse no aluno. Por fim, na terceira problematização, tensionamos o enunciado que afirma que música é matemática e, de forma mais geral, que a matemática está em tudo. Inspiramo-nos no conceito filosófico de ritornelo para pensar a docência em matemática a partir de exercícios de desterritorialização/reterritorialização no território da Educação Matemática.
\end{abstract}

Palavras-chave: Matemática e Música. Educação Matemática. Filosofia.

\begin{abstract}
In this paper we analyze a set of texts inserted in the research field of Mathematics Education that establish relations between mathematics and music, published in the last four editions of the Encontro Nacional de Educação Matemática (ENEM). Using Foucauldian discourse analysis as a methodology, we give visibility to the enunciations categorized from these articles, organizing them based on 3 problematizations. In the first, we consider the appropriation of music for the teaching of fractions, taking into account the historical context of Greek mathematics and the use of the symbols of musical notes according to their times. In the second, we analyze the enunciations that refer to naturalized methodological aspects in the teaching of mathematics, namely ludic aspectos and stimulating interest in the student. Finally, in the third problematization, we tension the statement that states that music is mathematics and, more generally, that mathematics is in everything. We are inspired by the ritornelo's philosophical concept to think teaching in mathematics from exercises of deterritorialization / reterritorialization in the territory of Mathematics Education.
\end{abstract}

\footnotetext{
1 alice.stephanie.ts@gmail.com, Doutora em Educação Científica e Tecnológica pela Universidade Federal de Santa Catarina, professora, Universidade Federal do Rio Grande do Sul, Tramandaí/Rio Grande do Sul/Brasil. 2 juliano.espezim@ufsc.br, Doutor em Educação Científica e Tecnológica pela Universidade Federal de Santa
Catarina, professor, Universidade Federal de Santa Catarina, Florianópolis/Santa Catarina/Brasil.
} 
Keywords: Mathematics and Music. Mathematics Education. Philosophy.

\begin{abstract}
Resumen
En este artículo analizamos un conjunto de textos insertados en el campo de investigación de la Educación Matemática que establecen relaciones entre las matemáticas y la música, publicados en las últimas cuatro ediciones del Encontro Nacional de Educação Matemática (ENEM). Utilizando el análisis del discurso de Foucault como metodología, damos visibilidad a las declaraciones clasificadas de estos artículos, organizándolas en base a 3 problematizaciones. En la primera, consideramos la apropiación de la música para la enseñanza de fracciones, teniendo en cuenta el contexto histórico de las matemáticas griegas y el uso de los símbolos de las notas musicales según su tiempo. En la segunda, analizamos declaraciones que se refieren a aspectos metodológicos naturalizados en la enseñanza de las matemáticas, a saber, la diversión y el interés estimulante en el estudiante. Finalmente, en la tercera problematización, tensionamos la afirmación que dice que la música es matemática y, en general, que la matemática está en todo. Nos inspira el concepto filosófico de ritornelo para pensar la enseñanza de las matemáticas a partir de ejercicios de desterritorialización / reterritorialización en el territorio de la Educación Matemática.
\end{abstract}

Palabras claves: Matemática y Música. Educación matemática. Filosofía.

\title{
1 Introdução
}

A relação entre música e matemática aliada principalmente àquela afirmação de que "a matemática está em tudo" parece estar naturalizada no discurso da Educação Matemática. Esta relação recebe destaque quando se trata de pensar a matemática presente no cotidiano, e recebe respaldo inclusive da mídia, em propostas educativas. Como exemplo podemos citar a propaganda nacional em torno da Olimpíada Brasileira de Matemática de Escolas Públicas (OBMEP) em 2020, conforme destaca o Instituto de Matemática Pura e Aplicada (IMPA):

Você pode até não entender de música. Mas não precisa ser nenhum especialista para notar que um instrumento pode emitir diferentes tipos de sons, se estiver com a corda inteira, dividida pela metade ou em três partes. E a resposta para isso está na matemática! Esta magia quase imperceptível entre notas musicais e números é o tema da 16ạ edição da Olimpíada Brasileira de Matemática de Escolas Públicas (IMPA).

Diante do apelo à realidade e à interdisciplinaridade, dentro das discussões entre professores de matemática, a música adquire visibilidade nas práticas pedagógicas no ensino desta disciplina. Para investigar como as relações entre matemática e música se destacam no discurso da Educação Matemática e de que forma evidenciam sua recorrência, analisamos artigos publicados no Encontro Nacional de Educação Matemática (ENEM) em suas quatro últimas edições, ocorridas em 2010, 2013, 2016 e 2019, contemplando uma década de pesquisas desenvolvidas. Os ENEMs, organizados a cada três anos pela SBEM, se configuram como um espaço onde circulam e se produzem verdades sobre o campo da Educação Matemática, pois tais encontros contam com a participação de professores da Educação Básica, professores e estudantes das Licenciaturas em Matemática, estudantes da Pósgraduação e pesquisadores que discutem questões referentes à Educação Matemática. 
Os trabalhos foram angariados a partir dos anais disponíveis nos sítios dos eventos, sendo classificados em comunicações científicas e relatos de experiência. A busca inicial foi feita a partir da palavra-chave "música" inserida nos títulos dos trabalhos. Dos 24 artigos encontrados, dois deles descrevem relações entre música e matemática por meio da construção de instrumentos musicais; três expõem a criação de paródias por alunos e professores para o ensino de algum conteúdo matemático; e 19 propõem o ensino de conteúdos matemáticos, principalmente de frações, por meio de elementos musicais.

Neste contexto, com base em algumas ferramentas da análise do discurso na perspectiva do filósofo Michel Foucault, buscamos analisar os enunciados mais recorrentes nesses trabalhos. Uma das ferramentas é o próprio entendimento de discurso que se caracteriza como um conjunto de enunciados que estão apoiados em uma mesma formação discursiva (FOUCAULT, 2008). No caso do discurso da Educação Matemática, podemos identificar diversos enunciados que podem ser formulados a partir da reunião de enunciações recorrentes, e no caso deste estudo, são os excertos extraídos dos artigos analisados.

Nesta perspectiva teórica e metodológica, cabe ressaltar que não pretendemos encontrar algo que estaria oculto nas enunciações ou aquilo que os autores supostamente quiseram dizer; nos preocupamos apenas com o que está dito em sua materialidade. Atentando a esta e as outras precauções metodológicas que Foucault (1996, 2008, 2011a, 2011b) estabelece, analisamos algumas verdades que circulam neste campo. Neste sentido, escolhemos os anais do ENEM por se constituir em um lugar privilegiado de fala e de circulação destas verdades. Ser professor, pesquisador ou estudante garante o acesso, mesmo que em condições diferentes, a esse espaço de discussão, pois como afirma Foucault (1996, p. 37), "ninguém entrará na ordem do discurso se não satisfazer a certas exigências ou se não for, de início, qualificado para fazê-lo". Assim, remetemo-nos ao ENEM entendendo-o como um lugar que comporta uma diversidade de sujeitos que possuem a função de produzir e veicular verdades sobre a Educação Matemática, visto que, segundo Foucault (2011a, p. 12):

Cada sociedade tem seu regime de verdade, sua "política geral" de verdade: isto é, os tipos de discurso que ela acolhe e faz funcionar como verdadeiros; os mecanismos e instâncias que permitem distinguir os enunciados verdadeiros dos falsos, [...] o estatuto daqueles que têm o encargo de dizer o que funciona como verdadeiro.

Neste ponto, é oportuno referenciar um conjunto de trabalhos que, a exemplo do intento deste artigo, tensionam verdades naturalizadas no campo da Educação Matemática e que são entendidas como enunciados, numa perspectiva foucaultiana. Problematizá-las se configura como uma tentativa de "sacudir a quietude com a qual as aceitamos; mostrar que elas não se justificam por si mesmas, que são sempre efeito de uma construção cujas regras devem ser conhecidas e cujas justificativas devem ser controladas" (FOUCAULT, 2008, p. 28). Esses trabalhos são os de Silva (2008) que versa sobre o enunciado "a matemática é difícil"; de Duarte (2009) que discute a importância de se trabalhar com a realidade do aluno; de Knijnik et al (2010) em que as autoras problematizam o uso de materiais concretos; de Quartieri (2012) no qual a autora interroga o uso da Modelagem Matemática; de Sartori (2015) que versa sobre a naturalização de aspectos lúdicos; de Góes (2015) que problematiza a formação do sujeito crítico; entre outros. 
Com este contexto problematizador, não se pretende substituir as verdades que orbitam a relação entre matemática e música por outro regime de verdade, porém nos permitimos questionar: Seria possível pensar de outra maneira tal relação? Como criar uma estratégia que nos permita não enxergar o campo da Educação Matemática apenas a partir de uma positividade estrita e inabalável?

Sendo assim, a proposta deste artigo é a de pensar estratégias de desorganizar, de desterritorializar, de desestabilizar o solo fixo das relações entre matemática e música para o ensino de matemática a partir de elementos filosóficos. Mas, "em que a filosofia pode servir a matemáticos, ou mesmo a músicos: mesmo e, sobretudo, quando ela não fala de música ou de matemática?" (DELEUZE, 2002, p. 225).

Ao encontro desta proposta, os estudos de Deleuze e Guattari (1997) nos apontam alguns caminhos. Para eles, a filosofia consiste na criação de conceitos que dão conta de certos problemas em um campo de imanência específico. Na posição de pesquisadores e professores, não de filósofos, fizemos um deslocamento, utilizando o conceito de ritornelo, explorado pelos autores supramencionados, para pensar em nosso campo de imanência: como sair de nosso território estratificado em que as relações entre matemática e música parecem naturalizadas? É possível deslocar-se para problematizar as verdades presentes nas pesquisas e práticas pedagógicas aqui analisadas?

Para ensaiar algumas respostas a estas questões organizamos três problematizações formuladas metodologicamente a partir da análise do discurso na perspectiva foucaultiana, e teorizadas com base em outros autores que possuem, em certa medida, uma aproximação no que se refere ao caráter problematizador. Na primeira delas, fazemos uma análise sobre a apropriação da música para o ensino de frações, levando em conta o contexto histórico da matemática grega do século VI a. C. Propomos uma possibilidade de pensar a história da matemática no ensino desta disciplina de outras formas. Na segunda problematização, analisamos enunciações que remetem a aspectos metodológicos naturalizados no ensino de matemática que se efetivam com o auxílio da música, a saber a ludicidade e atividades que estimulem o interesse do aluno, os quais são tensionados a partir da obra de Masschelein e Simons (2018). Por fim, na terceira problematização, recorremos a estes mesmos autores para colocar sobre suspeição o enunciado que afirma que música é matemática e, de forma mais geral, que a matemática está em tudo.

\section{Ritornelo}

Tomar os conceitos de Deleuze e deslocá-los para o campo, para o plano de imanência que é a Educação [Matemática] (GALLO, 2008, p. 53).

Uma primeira constatação acerca da filosofia para Deleuze é que ela não consiste em uma reflexão, o que para nós implicaria que filosofar no campo da Educação não seria fazer reflexões sobre e dentro deste campo de saber. A filosofia é definida por ele como criação de conceitos cuja noção não é aquela com a qual estamos familiarizados, pois ela exige uma desconstrução do que entendemos por conceito. Conforme afirma Gallo, "o conceito não é apenas um operador lógico; é mais que isso e menos que isso, na medida em que se coloca para além da lógica e para aquém da lógica" (GALLO, 2008, p. 40). Todo conceito é criado a partir de problemas, e [...] um problema deve ser posto pelo filósofo, para que os conceitos possam ser criados" (Ibidem, p. 40, grifos do autor). 
Outros autores que se debruçam sobre este entendimento de criação conceitual no campo da Educação como Tadeu, Corazza e Zordan (2004), para os quais a pesquisa educacional deve buscar uma fuga de uma imagem dogmática do pensamento. Para eles, um caminho consiste em pesquisar com base em uma criação pois,

\begin{abstract}
pesquisar é criar e criar é problematizar. [...] problematizar não significa responder a 'perguntas de pesquisa', [...] mas determinar os dados e as incógnitas do problema, desenvolver o máximo possível estes elementos em vias de determinação e encontrar os casos de solução correspondentes a esse desenvolvimento (TADEU, CORAZZA e ZORDAN,2004, p. 26-27).
\end{abstract}

Com base neste entendimento de criação, buscaremos desenvolver os elementos encontrados no material empírico e buscar respostas que não determinam uma verdade absoluta sobre o tema, mas possíveis resultados que objetivam problematizar nossa constituição de sujeito professor no campo da Educação Matemática. Sobre as pesquisas nesta perspectiva, Tadeu, Corazza e Zordan (2004, p. 32), afirmam o seguinte:

O mais elevado poder do pensamento desta pesquisa é a criação, não a faculdade da verdade, digna do paradigma lógico-cognitivo ou racionalista, mas a do novo, a da criação de sentido, própria da filosofia. Desse modo, os "resultados" e os conceitos criados por ela são sempre verdadeiros, segundo a verdade que eles conseguem produzir, introduzir no mundo, atravessar, passar. Eles são sempre, portanto, "resultados" indiscutíveis, não-criticáveis, já que a sua rejeição em favor de outros resultados-conceitos tem sempre por condição outros problemas de pesquisa e outras imagens do pensamento.

Dentro do escopo deste artigo, considerando este histórico de problematizações de verdades consideradas por nós como naturalizadas, propomos a operação com o conceito de ritornelo, criado por Deleuze e Guattari. Ritornelo é um conceito roubado por eles do campo da música que, em sua definição representacional, delimita um trecho musical que deve ser repetido em uma partitura. Os filósofos explicam o sentido restrito dado ao ritornelo como sendo agenciamentos produzidos pelo som:

Diríamos que o ritornelo é o conteúdo propriamente musical, o bloco de conteúdo próprio da música. Uma criança tranquiliza-se no escuro, ou bate palmas, ou inventa um passo, adapta-o aos traços da calçada (...). Uma mulher cantarola, "eu a ouvia cantarolando uma ária, com voz baixa, suavemente". Um pássaro lança seu ritornelo. A música inteira é atravessada pelo canto dos pássaros, de mil maneiras (...). A música é atravessada por blocos de infância e de feminilidade. A música é atravessada por todas as minorias e, no entanto, compõe uma potência imensa. Ritornelos de crianças, de mulheres, de etnias, de territórios, de amor e de destruição: nascimento do ritmo (DELEUZE; GUATTARI, 1997, p. 99-100).

Em um sentido mais amplo, na formulação do conceito filosófico, estes autores chamam de ritornelo "todo conjunto de matérias de expressão que traça um território, e que se desenvolve em motivos territoriais, em paisagens territoriais (há ritornelos motores, gestuais, óticos, etc.)" (Ibidem, p. 132). 
Para estes filósofos, o ritornelo se configura como um elemento de convergência de outros conceitos que eles se utilizam em seus estudos: território, reterritorialização e desterritorialização. Conforme estes autores, "o ritornelo está totalmente ligado ao problema do território, da saída ou entrada no território, ou seja, ao problema da desterritorialização. Volto para o meu território, que eu conheço, ou então me desterritorializo [...]" (Ibidem, p. 76). De acordo com Guattari e Rolnik (1996, p. 323) a noção de território

[...] é entendida num sentido muito amplo, que ultrapassa o uso que fazem dele a etologia e a etnologia. Os seres existentes se organizam segundo territórios que se delimitam e os articulam aos outros existentes e aos fluxos cósmicos. O território pode ser relativo tanto a um espaço vivido, quanto a um sistema percebido no seio do qual um sujeito se sente "em casa". O território é sinônimo de apropriação, de subjetivação fechada sobre si mesma. Ele é o conjunto de projetos e representações nos quais vai desembocar, pragmaticamente, toda série de comportamentos, de investimentos, nos tempos e nos espaços sociais, culturais, estéticos, cognitivos.

Destarte entendemos que a Educação Matemática pode se configurar como território, porto seguro no qual os professores formados em matemática, em sua maioria, buscam guarida para inicialmente pensar sobre o ensino de matemática. Neste campo, esta linha de pensamento que busca incessantemente encontrar respostas infalíveis para as reflexões oriundas da Educação Matemática, entendidas como formas ideais e inevitáveis de se ensinar e aprender matemática, se configura como um elemento linear e evolutivo dentro do campo.

Se aceitamos o ritornelo como forma de pensar dentro dele, precisamos realizar um processo de desterritorialização que, seguindo os autores supracitados, permitiria "abrir-se, engajar-se em linhas de fuga e até sair de seu curso e se destruir" (Ibidem, p. 323). Podemos ainda pensar em dois tipos de desterritorialização, a relativa e a absoluta. Uma explicação mais apurada encontra-se em Zourabichvili (2004), contendo discussões a respeito de outros conceitos essenciais, como é caso do devir, que parecem entrelaçados nas obras desses filósofos. Sobre a diferença entre as formas de desterritorialização o autor aponta:

Distingue-se uma desterritorialização relativa, que consiste em se reterritorializar de outra forma, em mudar de território (ora, devir não é mudar, já que não há término ou fim para o devir - [...]); e uma desterritorialização absoluta, que equivale a viver sobre uma linha abstrata ou de fuga (se devir não é mudar, em contrapartida toda mudança envolve um devir que, apreendido como tal, nos subtrai à influência da reterritorialização[...]). (ZOURABICHVILI, 2004, p. 23).

Entendemos que as atuais possibilidades de se aproveitar do conceito de ritornelo para pensar o campo da Educação Matemática se baseiam em uma perspectiva de desterritorialização relativa que exige um processo de reterritorialização. Uma interpretação deste conceito é que "a reterritorialização consistirá numa tentativa de recomposição de um território engajado num processo desterritorializante" (GUATTARI; ROLNIK, 1996, p. 388). Ou seja, reterritorializar, voltando ao território, mas compondo novos agenciamentos, essa seria a função do ritornelo. Neste sentido, Deleuze e Guattari (1997) afirmam que o ritornelo se constitui pelo nosso afastamento de casa, sendo que ao voltarmos para este lugar não seremos mais reconhecidos, pois a reterritorialização nunca é um retorno ao mesmo. 0 
começar novamente, o retornar, ancora-se na diferença. Em outras palavras, "Não há chegada, nunca há senão um retorno, mas regressar é pensado numa relação avesso-direito, recto-verso com partir, e é ao mesmo tempo que se parte e se regressa" (ZOURABICHVILI, 2004, p. 23).

O que seria, então, o processo de desterritorialização? O que significaria essa saída do território? Como, produzir ritornelos que nos permitam movimentos de saída neste território que é a Educação Matemática? Como mobilizar este conceito para materializar um processo de desterritorialização em um território constituído de quantidade significativa de matéria sólida (os discursos naturalizados do território) e que impedem o movimento dos fluxos? Como aproveitar estes fluxos e realizar um retorno ao território para que não possamos mais nos reconhecer, para que possamos repensar nossas práticas pedagógicas, especialmente aquelas em que utilizamos a música? Colocar em suspenso as verdades deste campo? A busca de outras? Na tentativa, tomamos um rumo um tanto incerto. Ainda territorializados, partimos de alguns extratos do território ligados a textos que versam sobre a matemática e a música e nos deixamos levar por agenciamentos que nos permitem filosofar no território.

\subsection{Primeira problematização: as frações e a música}

Esta problematização refere-se a duas relações feitas entre matemática e música e que dizem respeito a um conteúdo específico: as frações. A primeira delas se sustenta a partir de um viés histórico que envolve Pitágoras à criação do monocórdio, e a segunda, à duração das figuras de notas musicais utilizadas para compor partituras.

Nossa observação sobre a relação histórica proposta pelos autores a partir da criação do monocórdio por Pitágoras se baseia em um entendimento naturalizado de como as frações são apresentadas. Vejamos o que os autores dos trabalhos da base empírica afirmam sobre esta questão:

Pitágoras fez a importante descoberta de que as notas musicais eram alcançadas através de um sistema fracionário. Através dos testes realizados com o monocórdio, Pitágoras percebeu que ao minimizar o tamanho da corda, eram produzidos novos sons, e as vibrações aconteciam com uma frequência maior do que a anterior (REIS; MENDES; MILANI, 2019, p. 3).

Segundo a lenda, ao passar por uma oficina, Pitágoras ouviu o som de cinco martelos batendo em uma bigorna. Interessado pelos belos sons produzidos por essas pancadas, inicialmente pensando que a qualidade do som era originária da força das mãos, ele trocou os martelos, mas cada martelo conservava o som que lhe era próprio. Após tirar um martelo que não estava soando muito bem, Pitágoras pesou os outros quatro martelos, tendo como resultado doze, nove, oito e seis unidades de peso. Essas razões matemáticas dariam início à construção do primeiro experimento científico da história, o monocórdio (SANTOS; FERREIRA, 2010, p. 3).

A Matemática e a Música possuem laços profundos, conhecidos desde a Antiguidade. $O$ primeiro registro científico associado à Matemática e à Música ocorreu por volta do século VI a.C na Grécia Antiga, na escola Pitagórica. Segundo Abdounur (2003), os pensadores desta época relacionavam intervalos musicais com o conceito de frações, há mais de 2000 
anos, fazendo uso de um instrumento de corda denominado monocórdio (CAVALCANTI; LINS, 2010, p. 3).

Tentamos nesse dia simular a experiência de Pitágoras, mas, ao invés do monocórdio, fazê-la por meio de tubos de mangueira, tipo "Flauta Pã", visando explorar frações e relacionando com sons/intervalos musicais (BORGES; GOMES, 2010, p. 7).

Ainda na busca por materiais para as aulas de Matemática e Música, o grupo do RP verificou a necessidade de uma abordagem histórica de como nasceu à relação entre a Matemática e a Música. Dessa forma, o grupo optou por fazer, inicialmente, uma apresentação histórica sobre a antiga Grécia, referenciando o filósofo e matemático Pitágoras, que em seu trabalho demonstrou que as relações matemáticas serviram de base para as escalas musicais (OLIVEIRA; ANDRADE; SOUSA; SOUTO; 2019, p. 6).

Legitimando a criação do monocórdio a Pitágoras, os autores recorrem ao artifício de utilizar as frações para produzir sons específicos neste instrumento quando sua corda é pressionada em determinados lugares: na metade, 122 , na terça parte, $1 / 3$, na quarta parte, $1 / 4$. Em linhas gerais, nossa problematização se refere ao seguinte: Como mencionar as frações tais quais as representamos hoje quando se analisa o monocórdio, sendo que na Grécia do século VI a.C. os números eram representados de outra maneira? Remetermo-nos a um passado histórico não seria o mote para pensarmos sobre a matemática de antigas civilizações?

Ao recorrer ao trabalho de Roque (2012) sobre a História da Matemática, encontramos argumentos problematizadores sobre visões anedóticas da matemática do passado, considerando-as como produções estéreis que só visam uma suposta motivação dos alunos e que se configuram como uma tentativa de aproximar as construções geniais de matemáticos às pessoas mortais. Inclusive, diante do estudo sobre obras gregas, esta autora sugere que "a escassez de fontes, somada à convergência interessada dos únicos textos disponíveis, nos permite duvidar até mesmo da existência de um matemático de nome Pitágoras" (Ibidem, p. 91). Neste sentido, os detalhes do segundo excerto supracitado que chegam a descrever os procedimentos de Pitágoras, mostram um impulso dos pesquisadores em deflagrar uma história icônica, que seria muito difícil de ser apreendida nos registros históricos passados, uma forma de visibilizar um brilhantismo do pensamento e uma forma construção do conhecimento que nasce de lampejos de inteligência momentâneos.

De acordo com Roque (2012), na Grécia do século VI a.C., os números tinham uma representação geométrica: com base em unidades, formavam-se números triangulares, quadrados, hexagonais etc. De forma distinta, quatro séculos depois, na famosa obra de Euclides, Os Elementos, é interessante observar que os números são apresentados a partir de segmentos de reta, isto é, mesmo que de outra forma, preservou-se um entendimento geométrico dos números na civilização grega.

Diante desta forma representacional dos números dos gregos, diferente da nossa, os questionamentos que formulamos são os seguintes: como é possível recorrer ao monocórdio, supostamente criado por Pitágoras, e relacioná-lo às frações tais quais conhecemos? Diante da envergadura que os aspectos históricos têm no campo da Educação Matemática, não seria importante nos questionarmos sobre este tipo de operação que pode transmitir ao aluno um entendimento equivocado da representação numérica dos gregos? Não seria um desafio 
interessante tratar do monocórdio realizando um exercício de supor formas de representar razões com os elementos que supomos que tinham os gregos do período em questão?

A segunda relação feita entre música e matemática diz respeito ao ensino das operações entre frações a partir das figuras que representam os tempos das notas musicais. Como no quadro a seguir, retirado de um dos trabalhos analisados, observamos que cada figura musical e respectivamente a figura de pausa, possuem um valor:

Figura 1 - Tabela de equivalência entre notas e frações

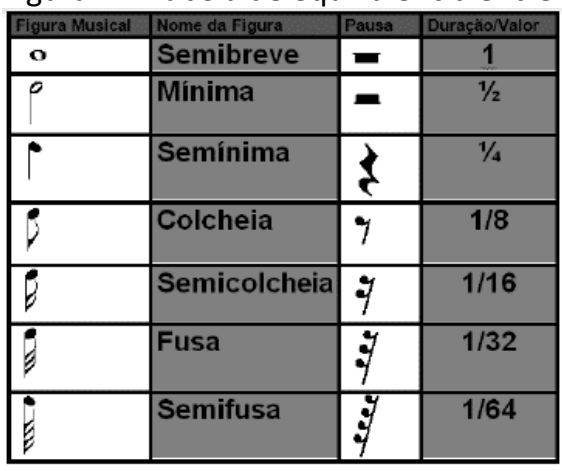

Fonte: Souza; Cruz (2016, p.5)

Estes símbolos são utilizados para ensinar representações e operações fracionárias. No caso da operação de adição, por exemplo, a soma de duas semicolcheias seria igual a uma colcheia. Vejamos como estas operações são tratadas pelas seguintes enunciações retiradas dos trabalhos analisados.

Ao observarmos a atividade 01 é possível identificar que seu objetivo é proporcionar ao educando o desafio de compor a combinação dos símbolos musicais, tendo como principal elemento matemático os conceitos de proporção e operações no conjunto dos números Racionais (REIS; MENDES; MILANI, 2019, p. 11).

A primeira atividade foi colocar uma música para os alunos e pedido para que eles contassem quantas batidas (acompanhando o andamento da música com a mão, ou o pé, por exemplo) por minuto a música possuía. A partir daí foi apresentada uma partitura, e explicados alguns conceitos básicos da linguagem musical, como pauta, clave, tempo, compasso, fórmula de compasso, sendo também apresentadas aos alunos as figuras rítmicas, tentando já aí relacionar matematicamente esse tema com frações (BORGES, GOMES, 2010, p. 3).

Conhecendo os valores de cada figura musical podemos realizar as quatro operações básicas da matemática que são soma, multiplicação; divisão e subtração para compor qualquer peça musical, dentro de cada compasso. Aproveitamos e trabalhamos as operações da seguinte forma: somando as frações, multiplicado e dividindo, gerando consequentemente o som característico (MEDEIROS, 2019, p. 11).

Como o objetivo do vídeo era mostrar como as frações mais simples regem o ritmo de uma partitura, foi pertinente mencionar os conjuntos numéricos tanto dos naturais quanto dos inteiros para definir os números racionais. 
Nesse momento, enfatizamos a necessidade de se criar um novo conjunto numérico (NUNES; RIBEIRO, 2019, p. 5).

Nesta oficina desenvolver-se-á um estudo de equações fracionárias, através de algumas operações matemáticas das frações dentro de uma partitura musical, transmitindo conceitos introdutórios da teoria musical e aprofundando no estudo em relação às fórmulas de compasso, unidades de tempos e de compasso, que são formadas por frações (SOUSA; CRUZ, 2016, p. 1).

Assim, a combinação dos símbolos dentro de um compasso na partitura resultaria em um procedimento de operar frações a fim de completar o tempo necessário. Contudo, concordamos com Vianna (2015) que este procedimento, em seu limite, acaba se convertendo em operações com números inteiros. Ao analisar trabalhos que sugerem o aprendizado de frações a partir da música, tal qual apontado pelas enunciações aqui apresentadas, o autor afirma:

Professores acreditam que podem ensinar frações através das notas musicais. Grande engano! [...] A primeira coisa que tentam fazer é forçar alunos a preencherem um compasso, por exemplo, de quatro tempos, usando notas de duração variadas. Não funciona $\rightarrow$ os alunos aprendem a operar com "equilíbrio"; se usam uma semicolcheia, sabem que terão que usar outra semicolcheia para obter um valor equivalente a uma colcheia, sempre aos pares, e assim fazem as operações necessárias, sempre com números inteiros. Ainda que a notação musical fique mais complexa, por exemplo através de "pontos" que aumentam o valor relativo das notas pela metade, rapidamente os alunos aprendem a colocar a nota que falta, com o tempo certo, para a soma dos tempos resultar um número inteiro (VIANNA, 2015, p. 51).

Outra consideração importante que este autor faz no contexto de suas análises sobre as relações entre música e matemática e que pode ser estendida às tentativas que os professores executam para facilitar o aprendizado da matemática é a de que a transferência de conhecimentos parece ser obtida a partir de uma mágica. Além disso, outra conclusão que Vianna faz e que extrapola esta relação com a música é a seguinte:

Posso dizer que o "erro" está em pretender que, ao ensinar a notação musical, aprenda-se matemática? Na verdade, ao se aprender a notação musical, aprende-se a ler e escrever música, ao se aprender a jogar xadrez, aprende-se a jogar xadrez, e é inútil tornar-se exímio digitador com a intenção secreta de tocar piano (Ibidem, p. 51).

As afirmações de Vianna podem soar para alguns como certo pessimismo ou até como uma crítica não construtiva. Contudo, a radicalidade de pensar nossa (de)formação de professores em termos de ritornelo, conforme afirmamos com base nos autores que nos oferecem as teorizações sobre o tema, poderia permitir, em seu viés de desterritorialização, "abrir-se, engajar-se em linhas de fuga e até sair de seu curso e se destruir" (GUATTARI; ROLNIK, 1996, p. 323). Ou seja, como professores, podemos e talvez deveríamos estar abertos à possibilidade de destruir algumas certezas referentes a nossas práticas pedagógicas. 
Enfatizamos nestas considerações o conteúdo referente às frações, pois este é o mais recorrente entre os trabalhos analisados de modo geral. No entanto, cabe apontar outros conteúdos apresentados quando se relaciona música e matemática buscando uma aproximação entre estas duas linguagens: "obtenção de um modelo em progressão geométrica, o estudo de valores de notas envolve os conteúdos de potenciação, fração, razão, proporção" (UMBEZEIRO, 2016, p. 2); "gráfico das freqüências das notas musicais [...] uma progressão geométrica com função exponencial” (GRAMS, MILÃO, 2013, p. 12); "representar as oscilações (frequência) graficamente e observar que os movimentos podem ser definidos por funções senóides. [...] A distância entre os trastes dos instrumentos de cordas obedece a uma lei matemática cuja distribuição é logarítmica" (OLEGÁRIO, ANDRADE, 2013, p. 3); "conceitos de contrações e expansões de curvas com variação de parâmetros de uma função" (HEITMANN, PINTO, 2010, p. 1); "som das palmas e das batidas dos pés, fazendo uma analogia dos números romanos e egípcios com os ritmos" (SANTOS, 2013, p. 4). No mesmo sentido que apontou Vianna (2015) a respeito das frações, poderíamos pensar que tais conteúdos relacionados à música ocasionariam uma mágica transferência de conhecimentos?

A apropriação destes conceitos da música garantiria o aprendizado da matemática escolar? Esta questão também parece perpassar alguns dos trabalhos, em que os próprios autores apontam as dificuldades de os alunos compreenderem aspectos da matemática:

Observou-se a necessidade de uma atenção maior para as questões puramente matemáticas, imaginadas anteriormente como de fácil assimilação pelos alunos, o que não ocorreu na realidade (BORGES; GOMES, 2010, p. 6).

As notas de campo revelaram a dificuldade dos alunos relacionarem gráficos e expressões algébricas a notas musicais sem o uso de sons. Além disso percebeu-se que os alunos ficaram confusos e não entenderam o motivo de relacionar as notas musicais e a representações matemáticas. A conexão entre esses fenômenos não estava clara no roteiro de trabalho e o objeto não permitia que manipulassem o piano (HEITMAN; PINTO, 2010, p. 6).

Este tipo de pensamento, mesmo que tenha aparecido em apenas dois dos trabalhos da base empírica, nos parecem exemplares para um exercício inicial de retorno ao território. Os professores buscariam na música substratos para mobilizar o ensino de matemática, supostamente fazendo uma saída de seus territórios no sentido ao campo da música e, ao retornarem para a prática elaborada, realizam um movimento que tensiona a própria prática, ao contrário dos outros trabalhos que se sustentam na suposta positividade dos efeitos da música sobre a matemática que se aproxima muito mais daquilo que se quer, do que daquilo que é.

Além disso, a preocupação dos autores aponta para a dificuldade dos estudantes no momento de implementação do conteúdo matemático em si, mesmo que a aula seja a priori divertida, interessante e contextualizada, conforme afirmam, o que nos leva a segunda problematização, referente aos enunciados que advém do discurso da Educação Matemática.

\section{Segunda problematização: Música para uma aula de matemática lúdica e interessante}

Com exceção de dois trabalhos analisados, todos eles dão ênfase às características que o ensino de matemática apresentaria quando abordado a partir da música: a matemática se 
tornaria interessante, contextualizada e divertida. Abordar a matemática por meio da música contemplaria dois aspectos: aqueles que abordam os conteúdos por meio de paródias e aqueles que desenvolvem uma abordagem matemática de algum aspecto da música, como é o caso das frações. Em ambos os casos, na maioria dos trabalhos, as propostas justificam-se pela importância de mobilizar o interesse dos estudantes, além de propiciar uma aula criativa e lúdica, ou seja, divertida e movida pelo prazer em aprender. Estes são os dois principais enunciados identificados, os quais problematizamos nesta seção.

Mas cabe evidenciar que eles aparecem entrelaçados a outras verdades do campo educacional ou mesmo da Educação Matemática, como por exemplo: o ensino de matemática não deve ser pautado na memorização mecânica de regras e fórmulas; o professor deve estimular no aluno o desenvolvimento de atitudes como: a capacidade de expressão, autoestima, sociabilidade, etc; é importante que a matemática seja trabalhada de forma interdisciplinar; dentre outras. As enunciações abaixo apontam as principais justificativas para uma boa aula de matemática, objetivo supostamente alcançado por meio do uso pedagógico da música, segundo os autores:

A composição descrita acima, do grupo de alunos da Banda Estudando os Polinômios, retrata o tema Polinômios de uma forma lúdica, não se detendo a memorização de procedimentos e regras (CAVALCANTI; LINS, 2010, p. 8).

Tais experiências foram reveladoras, dinâmicas e criativas. $O$ aumento de suas capacidades de expressão ficou evidente e a aprendizagem ocorreu de forma agradável e prazerosa (MENDONÇA; SOUSA, 2010, p. 2).

Observou-se que um ambiente diferente dos modelos tradicionais de aula proporciona maior interesse. Pois, para o aluno, o que aparentemente era algo apenas lúdico ou cultural, tornou-se uma aula de Matemática prazerosa (OLIVEIRA; ANDRADE; SOUSA; SOUTO, 2019, p. 9).

Os educandos através da Matemática com Música puderam elevar sua autoestima, promover a desinibição, estimular o interesse por diversos tipos de música, cultivar a sociabilidade, expressarem seus conhecimentos, sentimentos e indagações (SOUZA; TIAGO, 2016, p. 3).

Podemos descobrir, através de pesquisas, observações e no desenvolvimento de planos de aula, o quanto a Matemática pode ser alegre, divertida e contextualizada de forma interdisciplinar (SANTOS, 2013, p. 9).

O aspecto lúdico e a questão do interesse nas aulas de matemática, em especial propiciadas pela música, estão ligados ao enunciado que abordaremos na seção seguinte que afirma que "música é matemática", ou seja, no limite, se ancoram nas justificativas de que a matemática está em tudo. Assim, se a música faz parte do cotidiano do aluno e o diverte em suas atividades diárias, trazê-la para o ensino conferiria à escola a função de garantir o prazer do divertimento e mobilizar o interesse pelas atividades escolares. A matemática em especial ganha visibilidade neste cenário por ser considerada difícil e por fazer parte da linguagem musical.

Se recorrermos à perspectiva foucaultiana, encontramos pesquisas que problematizaram enunciados naturalizados no campo da Educação Matemática, como a questão da ludicidade. O trabalho de Sartori (2015) relaciona o lúdico no ensino de 
matemática à constituição do sujeito contemporâneo no discurso da Educação Matemática. A autora mostrou as justificativas atribuídas por professores para a utilização do lúdico nas aulas de matemática, e dentre as mais recorrentes está a de que o aluno deve ter o desejo de aprender matemática - da mesma forma fica evidente a questão do interesse; e ainda a de que os alunos precisam aprender com prazer; entrelaçada a estas duas, aparece a importância da satisfação do aluno ao aprender brincando. As enunciações referentes a essas justificativas mostraram uma possível interlocução entre as práticas lúdicas e um dos aspectos da sociedade contemporânea, a necessidade de nos constituirmos enquanto sujeitos consumidores. A investigação sugeriu que as práticas lúdicas, consideradas como uma forma de governamento posta a operar nas aulas de matemática, produzem efeitos na constituição dos sujeitos, especificamente em sua faceta de consumidor.

Ao olhar para este tema, para além de uma perspectiva foucaultiana, podemos pensar por meio destes enunciados sobre a função da escola e, em que medida poderíamos colocar em suspensão o ensino de matemática lúdico que ocorre através da música. Para tanto, Masschelein e Simons (2018) nos abrem algumas possibilidades.

Os autores apontam e problematizam algumas acusações feitas à escola na contemporaneidade, e dentre elas está a desmotivação da juventude. A partir desta categoria emergem diversos enunciados como aquele que afirma que os jovens não gostam da escola, ou de que não aprendem, pois as aulas não são divertidas, ou ainda, que o bem-estar não é priorizado na escola que deve também ser um espaço de lazer, conforme destacam os autores a partir dos argumentos analisados no contexto educacional. Nesta linha de pensamento, "o ideal é, e continua sendo, a "aprendizagem lúdica". O tédio é mortal. É hora de acabar com as aulas descomprometidas e os professores maçantes" (Ibidem, p 16). Os "acusadores" da escola criticam a estagnação desta instituição, defendendo que ela coloque as escolhas e necessidades dos jovens a frente do aprendizado. Vemos aqui uma crítica que os autores fazem a essa idealização de escola na contemporaneidade: “[...] vamos argumentar que a escola não é sobre o bem-estar, e que falar em termos de (des)motivação é o sintoma infeliz de uma escola enlouquecida, que confunde atenção com terapia e gerar interesse com satisfazer necessidades" (Ibidem, p. 17).

Dentre as táticas que a escola encontraria para driblar esse tédio instalado no aprendizado, está a popularização, que seriam técnicas de entretenimento que os professores utilizam na sala de aula, buscando transformar os alunos em espectadores e ouvintes. 0 objetivo, atentam os autores, é fugir de uma aula entediada, considerada como fracasso do professor. Como efeito desta popularização, ao tentar se aproximar do mundo dos alunos buscando dar-lhes prazer e relaxamento, ocorre uma "domação da tensão exigida pelo estudo e a prática" (Ibidem, p. 128). Ao professor parecem atribuir a função de um programa de televisão, comparam os autores, cujo objetivo é manter o espectador "colado à tela". Neste contexto, eles fazem uma crítica a esse esforço exacerbado da escola em atender os desejos do aluno:

Nosso ponto não é que a aprendizagem não pode ocorrer de forma lúdica, descontraída. Nosso ponto é que a escola consiste em outra coisa: a atenção para a matéria, mediada através da sala de aula, arranca os alunos de seu mundo e os coloca "dentro do jogo". A tensão não é convertida em relaxamento, mas em esforço (Ibidem, p. 128). 
A escola, afirmam, deve priorizar a formação ao invés do relaxamento, ou seja, permitir que o estudante se concentre na matéria, expandindo o seu mundo - o fora da escola - para que o aprendizado se efetive. Tentar contornar este encantamento provocado pelo relaxamento, pelo prazer em aprender, pode ser desagradável e ocasionar o tédio, porém não há necessidade de eliminá-lo, pois

[...] muitas vezes, são justamente esses momentos de tédio ou desinteresse que são impregnados com o potencial de, de repente, explodirem em algo interessante. Não estamos fazendo aqui um apelo ao tédio e à monotonia. Estamos fazendo um apelo contra a tendência comum de imediatamente problematizar e propor um corretivo para tudo que pertence à condition humaine et scolaire (Ibidem, p. 129).

Sendo assim, mobilizados pela reflexão de Masschelein e Simons (2018), seria possível justificar o uso da música no ensino de matemática para além de tornar a aula lúdica e interessante? Os argumentos dos autores nos oferecem potência para sairmos do lugar comum do território da Educação Matemática, problematizando estas verdades sobre o prazer e o interesse em aprender. Não estaríamos aprisionados neste território e reféns de um discurso de senso comum de que a matemática tem que ser divertida e prazerosa e, em alguns casos, talvez deixando o conteúdo matemático à margem?

\section{Terceira problematização: música é matemática?}

O enunciado que aparece com mais recorrência nos trabalhos analisados é aquele que afirma que música é matemática, que parece ser sustentado pelo enunciado mais amplo que sugere que a matemática está em tudo! A música, para fins pedagógicos, daria sentido a alguns conteúdos matemáticos que parecem descontextualizados da realidade, conforme afirmam os autores. A linguagem musical se aproxima da linguagem matemática ou até mesmo são consideradas a mesma linguagem pelos autores, legitimando o uso da primeira no ensino da segunda. Vejamos algumas enunciações que evidenciam esta relação:

Como mencionado, a música tem sua linguagem totalmente pautada sobre a matemática (SILVA; CRUZ; RIBEIRO, 2019, p. 2).

Atualmente existem diversas definições para música. Mas, de um modo geral, ela é considerada ciência e arte, na medida em que as relações entre os elementos musicais são relações matemáticas e físicas; a arte manifestase pela escolha dos arranjos e combinações (CAVALCANTI; LINS, 2010, p. 1).

Quando ouvimos um concerto musical ou apreciamos um instrumento construído por um Luthier, muitos de nós não atentamos para o fato de que por trás dessas duas artes existem inúmeras relações matemáticas. Desde a antiguidade se sabe sobre o enlace harmonioso entre a matemática e a música (BORGES; GOMES, 2010, p. 1).

Quanto aos aspectos positivos, foi ressaltada a ideia do discente ter a liberdade de trabalhar algum conteúdo do seu interesse e relacioná-lo à matemática, exercendo uma forma de interdisciplinaridade e de mostrar que a matemática "está presente em tudo", contribuindo assim para aprendizagem significativa (NUNES; RIBEIRO, 2019, p. 8). 
A música pode ser entendida como uma aplicação da matemática, uma vez que, a harmonia musical é gerada respeitando padrões e regularidades de uma estrutura lógica. "A matemática estuda a regularidade presente nas formas e nos números (GRAMS; MILÃO, 2013, p. 9).

[...] nem todos gostam de Matemática, mas quase todos gostam de Música. Porém, o que se percebe na Música são padrões rítmicos, harmônicos e melódicos, ou seja, a presença da Matemática nesta forma de arte (OLEGÁRIO; ANDRADE, 2013, p. 1).

Como podemos atentar nos excertos, a linguagem musical a que se referem e suas possíveis relações com a matemática estão nos arranjos, na harmonia, nas regularidades, no ritmo, na melodia, e na construção dos instrumentos musicais, relações estas que se fazem presentes desde a antiguidade. Por outro lado, a suposta ligação entre música e matemática é estabelecida pelas afirmações de grandes filósofos e matemáticos como Platão, Leibniz, Aristóteles e, como vimos anteriormente, Pitágoras. O seguinte excerto exemplifica este aspecto:

A verificação de que a música é um conjunto de relações sonoras e simbólicas remete a célebre frase de Leibniz, [...] "A música é um exercício oculto de aritmética de uma alma inconsciente que lida com os números" (GRAMS; MILÃO, 2013, p. 3).

Além disso, outros elementos legitimam esta aproximação entre música e matemática, como o fato de ela estar inscrita em documentos e avaliações de matriz governamental, como é o caso dos Parâmetros Curriculares Nacionais (PCN) e do Exame Nacional do Ensino Médio (ENEM):

[...] destacamos que em nossa busca de elementos que tivessem ligados a esta temática, nos deparamos com uma atividade proposta no Exame Nacional do Ensino Médio (ENEM) de 2009 uma questão que envolvia justamente a junção da música com a matemática, o que faz fortalecer ainda mais nossas considerações [...] (REIS; MENDES; MILANI, 2019, p. 16).

De acordo com os Parâmetros Curriculares Nacionais (2000) a Matemática está presente em várias atividades da vida cotidiana inclusive na Música. 'Possivelmente, não existe nenhuma atividade da vida contemporânea, da música à informática, do comércio à meteorologia, da medicina à cartografia, das engenharias às comunicações, em que a Matemática não compareça de maneira insubstituível [...]. (BRASIL, 2000, p.9.) (OLEGÁRIO; ANDRADE, 2013, p. 2).

Estes conjuntos de enunciações garantiriam uma sustentação teórica e metodológica entre matemática e música. Contudo, ao se levar em conta o entendimento naturalizado de que a matemática atua de forma decisiva sobre outras áreas de saber, conforme aponta Bampi (1999), a matemática, dentro do próprio discurso da Educação Matemática, assume a posição de um saber que produz verdades e efeitos de poder. Na racionalidade ocidental, a matemática é compreendida como a linguagem que descreve a natureza e que pode, assim, conhecê-la e dominá-la. Desta forma, um dos enunciados recorrentes é o de que a matemática 
está em toda parte, ou em outras palavras, de que tudo é matemática, o que remete à disposição deste saber como "essência" dos objetos do mundo empírico:

"todo o mundo usa a Matemática em tudo"; "a Matemática é a base de tudo"; "as pessoas não poderão realizar-se plenamente devido a deficiências básicas em sua formação Matemática"; "conhecer Matemática é condição para atuação crítica do indivíduo na sociedade"; "a sociedade como um todo está impregnada de Matemática", etc. (BAMPI, 1999, p. 133).

Tal verdade parece explicitar o quanto muitos pesquisadores sustentam suas narrativas numa tentativa de mostrar a importância da matemática em uma sociedade que questiona sua legitimidade no âmbito educacional, especialmente pelos resultados insatisfatórios do alunado em avaliações de grande escala. Por outro lado, o campo não está imune aos efeitos de verdade que esta operação produz, pois faz permear na Educação Matemática os efeitos de neutralidade e de universalidade da matemática conforme discute Duarte (2011), ao encontro do que aponta Bampi (1999), e que nos fazem perceber a matemática como uma ciência atemporal, asséptica e suficiente para determinar vereditos em outras áreas de saber.

De encontro a este movimento de relacionar a matemática ao mundo exterior da escola, Masschelein e Simons (2018) defendem esta instituição como um espaço de tempo livre, onde seria possível "suspender ou dissociar certos laços com a família dos alunos e o ambiente social, por um lado, e com a sociedade, por outro, a fim de apresentar o mundo aos alunos de uma maneira interessante e envolvente" (Ibidem, p. 6). Em outras palavras, o que os autores sugerem é que possamos dissociar, no momento presente da escola, os conteúdos escolares das práticas que são exteriores a ela. Este é justamente um dos argumentos em defesa de uma escola cuja definição é um espaço de tempo livre:

Devemos experimentar modos de organizar e projetar escolas para criar um espaço dedicado e tempo separado daquele da família, da economia e da esfera política. Esse deveria ser um tempo e espaço que não é caracterizado pelo uso multifuncional, circulação permanente e serviços flexíveis prestados a pessoas com necessidades pessoais de aprendizagem e percursos individuais de aprendizagem voltados para maximizar ganhos de aprendizagem. Mas sim um tempo e espaço que permanece isolado e ajuda a permitir um interesse partilhado no mundo; um momento e espaço tranquilos em que se pode viver, um tempo e lugar onde as coisas podem surgir em si mesmas e cuja funcionalidade está temporariamente suspensa (Ibidem, p. 87).

Assim, cabe destacar a comparação e dissociação que os autores fazem a respeito da motivação e do interesse, que atravessam o discurso da importância do cotidiano extraescolar na escola. Como então, gerar interesse por parte dos estudantes sem, no entanto, incumbir à escola, por meio do currículo de matemática, a função de trazer as questões próprias do cotidiano, como a música, por exemplo? Uma alternativa, segundo os autores, seria tornar a matemática, bem como outras práticas e linguagens, como objeto de estudo, visto que

A linguagem da matemática consegue ser autossuficiente - o seu enraizamento social é suspenso - e, por meio disso, ela se torna um objeto de estudo. Da mesma forma, podemos qualificar habilidades em prol da 
prática de habilidades. Nesse caso, a escola é o tempo e o lugar para estudo e prática - as atividades escolares que podem alcançar um significado e um valor em si mesmas. Mas isso não significa que a escola, como uma espécie de torre de marfim ou ilha, se refira a um tempo ou lugar fora da sociedade. O que é tratado na escola está enraizado na sociedade, no cotidiano, mas transformado pelos atos simples e profundos de suspensão (temporária) e profanação. Focamos em matemática em prol da matemática, em linguagem pelo bem da linguagem, em cozinhar por causa de cozinhar, em carpintaria por amor à carpintaria (Ibidem, p. 21).

Aproveitamos aqui o exemplo da linguagem matemática explanado pelos autores, e questionamos: Seria necessário, portanto, recorrer à linguagem musical para gerar interesse pela linguagem matemática? Para além do uso que se possa fazer da matemática, esse objeto de estudo exige esforço, pois, segundo os autores, o papel da escola é focalizar a atenção, o que em outras palavras se expressa por um cuidado especial e interesse pelas coisas. Neste caso, o que se estuda torna-se parte do mundo, não algo que sabemos sobre o mundo, mas "parte do mundo em que/pelo qual estamos imediatamente envolvidos, interessados, curiosos, e assim também algo que se torna um interesse" (Ibidem, p. 26).

Tornar algo real e significativo, portanto, não se expressa na conexão com a realidade, mas em despertar o interesse naquilo que nos faz pensar, como um assunto que importa. Portanto, o ambiente escolar "se torna um tempo/espaço do interesse - do que é compartilhado entre nós, o mundo em si [...] torna o indivíduo atento e garante que as coisas - destacadas de usos privados e posições - tornem-se "reais"” (Ibidem, p. 27). Ao se tornar real, este objeto de estudo deixa de ser apenas uma ferramenta ou recurso, mas algo que nos faz pensar, estudar e praticar.

\section{Considerações finais}

A exemplo de outros trabalhos no campo da Educação Matemática, buscamos problematizar as relações entre música e matemática que se dão de forma naturalizada em pesquisas e práticas pedagógicas. Por mais que pareça um movimento de negar estas práticas, o que se pretende é uma desestabilização, uma provocação, para que se possa inferir a possibilidade de pensar de outras maneiras.

Seria equívoco pensar que a relação estabelecida pelos trabalhos aqui analisados se configura como uma saída do território da Educação Matemática, pois a operação realizada pelos autores é a de olhar a música com as lentes da matemática. Parece mais uma permanência no território tal qual um movimento centrípeto de atrair outros saberes para o campo, aproveitando o entendimento de que a matemática estaria em tudo. Sair do território consistiria, por exemplo, na criação de fluxos que irromperiam os clichês de pensamento, buscando outras possibilidades reflexivas, como é o caso da tentativa que buscamos empreender neste artigo.

Com o ritornelo, nosso objetivo não foi o de guiar uma saída do território da Educação Matemática para o da música, mas de pensar neste movimento de saída, independente do território que se escolha. Parecemos estar tão aprisionados nas verdades que circulam no campo, pois para todo objeto exterior, vemos matemática e, consequentemente, reforçamos a metanarrativa de que a matemática está em tudo. 
Talvez este seja um cuidado que possamos ter para exercitar um processo de desterritorialização: ressignificar o entendimento de que valorizar o saber matemático com argumentos relacionados à suposta amplitude da matemática, não diga respeito ao nosso campo de pesquisa. Precisamos tentar escrever outras histórias, fundamentadas cientificamente, evidentemente, além de não perder o foco na matemática. Por incrível que pareça, ir de encontro a esta necessidade incessante de buscar relações da matemática "com tudo", pode fazer do estudo deste saber por ele mesmo, conforme Masschelein e Simons (2018), uma saída do território.

\section{Referências}

BAMPI, Lisete. Efeitos de poder e verdade do discurso da Educação Matemática. Educação e Realidade. 24 (1). jan./jun. 1999. p. 115-143.

BORGES, Fábio Alexandre. GOMES, João Paulo Cechella. Matemática e música: Uma proposta de abordagem no ensino fundamental. In: Anais do X Encontro Nacional de Educação Matemática, Salvador, 2010.

CAVALCANTI, Valdir de Sousa. LINS, Abigail Fregni. Ensino e aprendizagem da matemática através da música no Ensino Médio. In: Anais do X Encontro Nacional de Educação Matemática, Salvador, 2010.

DELEUZE, Gilles. GUATTARI, Félix. Mil Platôs: Capitalismo e Esquizofrenia. Vol. 4. São Paulo: Ed. 54, 1997.

2002.

O que é a Filosofia?. Trad. Bento Prado Jr. e Alberto Alonzo Muñoz. Rio de Janeiro: Ed.34,

DUARTE, Claudia Glavam. A "realidade" nas tramas discursivas da educação matemática escolar. Tese (Doutorado em Educação) Programa de Pós-Graduação em Educação, Universidade do Vale do Rio dos Sinos, São Leopoldo, 2009.

. Produzindo fissuras nas 'verdades' da matemática. In: HENNING, P., RIBEIRO, P; SCHIMIDT, E. (Org.). Perspectivas de investigação no campo da Educação Ambiental \& Educação em Ciências. Rio Grande: FURG, 2011.

FOUCAULT, Michel. A ordem do discurso. Edições Loyola: São Paulo, 1996.

. A arqueologia do saber. Michel Foucault; tradução de Luiz Felipe Baeta Neves, -7ed. - Rio de Janeiro: Forense Universitária, 2008.

. Microfísica do poder. Rio de Janeiro: Edições Graal, 2011a.

. Vigiar e Punir: nascimento da prisão. Petrópolis, RJ: Vozes, 2011 b.

GALLO, Sílvio. Deleuze \& a Educação. Belo Horizonte: Autêntica, 2008.

GOES, Aline de. Tornar o aluno crítico: enunciado (in)questionável no discurso da matemática escolar. Dissertação (Mestrado em Educação Científica e Tecnológica). Programa de Pós-Graduação em Educação Científica e Tecnológica. Universidade Federal de Santa Catarina, Florianópolis, 2015. 
GRAMS, Ana Laura Bertelli. MILÃO, Silvia Monteiro. Modelação matemática no ensino médio: A matemática por meio da música. In: Anais do XI Encontro Nacional de Educação Matemática, Curitiba, 2013.

GUATTARI, Félix; ROLNIK, Suely. Micropolítica: Cartografias do Desejo. 4 ed. Petrópolis: Vozes, 1996.

HEITMANN, Felipe Pereira. PINTO, Márcia Maria Fusaro. Uma abordagem musical, interativa e dinâmica para contrações e expansões de curvas variando parâmetros. In: Anais do X Encontro Nacional de Educação Matemática, Salvador, 2010.

IMPA - Instituto de Matemática Pura e Aplicada, 2020. Música e Matemática é tema da 16a edição da OBMEP. Disponível em: https://impa.br/noticias/musica-e-matematica-e-tema-da-obmep-2020/. Acesso em 20/04/2020.

KNIJNIK, Gelsa; WANDERER, Fernanda; DUARTE, Claudia Glavam. De las investigaciones pedagógicas. Uno: Revista de Didáctica de las Matemáticas, v. 17, n. 55, 2010. p. 81-93.

MASSCHELEIN, Jan; SIMONS, Maarten. Em defesa da escola: uma questão pública. 2 ed. Belo Horizonte: Autêntica Editora, 2018.

MEDEIROS, Zezito Gomes de. Ensino de matemática com música: em um contexto etnocultural. In: Anais do XIII Encontro Nacional de Educação Matemática, Cuiabá, 2019.

MENDONÇA, Silvia Regina Pereira de. SOUSA, Enne Karol Venancio de. Matemática e música: Cantando também se aprende. In: Anais do X Encontro Nacional de Educação Matemática, Salvador, 2010.

NUNES, Maria Carolina. RIBEIRO, Valdeane Silva. Da música às frações: reflexões sobre a elaboração e o uso de uma vídeo-aula. In: Anais do XIII Encontro Nacional de Educação Matemática, Cuiabá, 2019.

OLEGÁRIO, Príscila Gomes. ANDRADE, Ana Paula Rangel de. Frações: "afinando" as linguagens matemática e musical. In: Anais do XI Encontro Nacional de Educação Matemática, Curitiba, 2013.

OLIVEIRA, Valmir Alves de. ANDRADE, Luciano Roberto Padilha de. SOUSA, Geneci Alves de. SOUTO, Kelling Cabral. A música na formação dos professores de matemática do programa residência pedagógica. In: Anais do XIII Encontro Nacional de Educação Matemática, Cuiabá, 2019.

QUARTIERI. Marli Teresinha. A Modelagem Matemática na escola básica: a mobilização do interesse do aluno e o privilegiamento da matemática escolar. Tese (doutorado). 199f. 2009. Universidade do Vale do Rio dos Sinos, Programa de Pós-Graduação em Educação, São Leopoldo.

REIS, Enoque da Silva. MENDES, Hemerson Milani. MILANI, Samanta Margarida. Estudando frações nas relações entre a música e a matemática. In: Anais do XIII Encontro Nacional de Educação Matemática, Cuiabá, 2019.

ROQUE, Tatiana. História da matemática. Rio de Janeiro: Zahar, 2012.

SANTOS, Tarcisio Rocha dos. FERREIRA, Alessandra da Silva. Construções matemáticas da música. In: Anais do X Encontro Nacional de Educação Matemática, Salvador, 2010. 
SANTOS, Willian Monteiro dos. Música: Uma ferramenta interdisciplinar para o ensino de matemática. In: Anais do XI Encontro Nacional de Educação Matemática, Curitiba, 2013.

SARTORI, Alice Stephanie Tapia. O lúdico na Educação Matemática Escolar: Efeitos na constituição do sujeito infantil contemporâneo. 2015. 125f. Dissertação (Mestrado em Educação Científica e Tecnológica) Universidade Federal de Santa Catarina, Florianópolis, 2015.

SILVA, Fabiana Boff de Souza da. A (prender) matemática é difícil: problematizando verdades do currículo escolar. 118 f. 2008. Dissertação (Mestrado em Educação). UNISINOS: São Leopoldo, 2008.

SILVA, Paulo Vilhena da. CRUZ, Jaqueline Valerio da. RIBEIRO, Alana Brenda Pinheiro. As relações entre a música e matemática como estratégia pedagógica no ensino fundamental. In: Anais do XIII Encontro Nacional de Educação Matemática, Cuiabá, 2019.

SOUZA, Izabel Simone. TIAGO, Graziela Marchi. As possibilidades do ensino de matemática com música no ensino fundamental. In: Anais do XII Encontro Nacional de Educação Matemática, São Paulo, 2016.

SOUSA, Taíze Cardoso de. CRUZ, Antonio Messias Lopes. Matemática na educação musical: curso de formação para o professor de matemática. In: Anais do XII Encontro Nacional de Educação Matemática, São Paulo, 2016.

UMBEZEIRO, Denis de Aquino. Modelagem matemática - uma alternativa metodológica para o ensino de matemática por meio da música. In: Anais do XII Encontro Nacional de Educação Matemática, São Paulo, 2016.

VIANNA, Carlos Roberto. Sinfonia n. 5 em Dó menor. Zetetike, v. 23, n. 1, p. 45-57, 2015.

TADEU, Tomaz; CORAZZA, Sandra; e ZORDAN, Paola. Linhas de Escrita. Belo Horizonte: Autêntica, 2004.

ZOURABICHVILI, F. O vocabulário de Deleuze [versão eletrônica]. Tradução André Telles Rio de Janeiro. 2004. 